
\title{
3 Research Square \\ The effect of extracellular matrix on myogenic induction of adipose mesenchymal stem cells
}

\section{Wenyong Fei}

Northern Jiangsu People's Hospital

bin xie

Dalian Medical University

Ying Liu

Dalian Medical University

Mingsheng Liu

Dalian Medical University

\section{Xuanqi Wang}

Dalian Medical University

Yao Zhang

Dalian Medical University

\section{Shichao Cao}

Dalian Medical University

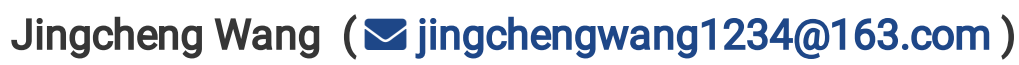

Department of orthopeadics and orthopeadics institute, Northern Jiangsu People's Hospital, clinical Medical college, Yangzhou University

\section{Lianqi Yan}

Northern Jiangsu People's Hospital

Ming Pei

West Virginia State University

\section{Research}

Keywords: ADSCs, ECM, 5-azacytidine, Myogenic differentiation

Posted Date: April 20th, 2020

DOI: https://doi.org/10.21203/rs.3.rs-23048/v1

License: (9) (i) This work is licensed under a Creative Commons Attribution 4.0 International License. Read Full License 


\section{Abstract}

Bankground: As one of the hot cells in the field of regenerative medicine, adipose mesenchymal stem cells(ADSCs) have been proved to have the ability of myoblast differentiation, but the disadvantage is that the efficiency of myoblast differentiation is not very high.Extracellular matrix(ECM), as a mixture of cytokines and proteins secreted by cells, is the substance secreted by cells. It has the advantages of nontoxic and harmless, and can provide the necessary material and environmental basis for cell growth and development.This study was to explore whether the myogenic differentiation potential of ADSCs cultured in ECM was improved.

Method: ADSCs were extracted from subcutaneous fat of male SD rats at the age of 3 months and weight $250 \mathrm{~g}$. The third generation cellular of ADSCs were prepared for ECM Xand the ECM was contained in the culture bottle for amplify the ADSCs. Myogenic induction was performed by 5 -azacytidine using the same generation of ADSCs cultured with ECM and non-ECM.

Result: ECM can significantly increase the rate of cell proliferation $(P<0.05)$.Immunofluorescence detected the expression of $\beta$-actin, Myod and Desmin in cells , and showed no significant difference in the expression of $\beta$-actin between groups $(P>0.05)$. However, there were significant differences in Myod and Desmin between groups $(P<0.001)$.RT-PCR showed that the mRNA expressions of myosin heavy chain $(\mathrm{MHC})$, troponin, Myogein and Myf5 were significantly different among groups $(P<0.001)$.

Conclusion: ECM culture of ADSCs can improve its growth rate and myogenic differentiation potential.

\section{Introduction}

Many patients have muscle damage or degenerative diseases. Although there is a small number of muscle satellite cells in muscle tissue to regenerate lost skeletal muscle cells, their number is too small to repair major defects[1,2]. Only relying on the body's own ability and the effects of drugs to recover can not well meet the needs of muscle recovery.At present, the application of mesenchymal stem cells in regenerative medicine has become the focus of attention because of its self-renewal, immunoregulation and lineage differentiation to mesoderm $[3,4]$.This kind of ability is a remarkable property of mesenchymal stem cells, making them powerful cellular candidates for use in regenerative medicine. Adipose mesenchymal stem cells, as one of the hot research cells, have been proved to have the ability of myogenic differentiation, but the deficiency is that the efficiency of myogenic differentiation is not very high, which limits its further clinical research.The ECM, as a mixture of cytokines and proteins secreted by the cell itself has the advantages of non-toxic and harmless. The study of Pei showed that ECM can not only increase the amplification rate of human synovial stem cells [5], but also improve the chondrogenic potential of human synovial tissue stem cells[6-9].

So far there was little research about the effect of myogenic differentiation of ECM on ADSCs .In this study, we hypothesized the ECM from ADSCs could significantly amplify the proliferation and improve myogenic differentiation potential of ADSCs. 


\section{Methods}

\subsection{Extraction of ADSCs}

A 3-month-old male SD rat weighing about $250 \mathrm{~g}$ was taken, and the rat was executed by intraperitoneal injection of $3 \mathrm{ml} 10 \%$ glyoxyl hydrate. The rat was routinely sterilized by lodophor. Subcutaneous fat was taken from the rats and the blood vessels and subcutaneous tissue were removed from the fat on the ultra-clean platform.The adipose tissue was cut into pieces and transferred into a $15 \mathrm{ml}$ centrifuge tube. The PBS buffer was blown repeatedly for many times, and left for 1 minute to absorb the excess PBS

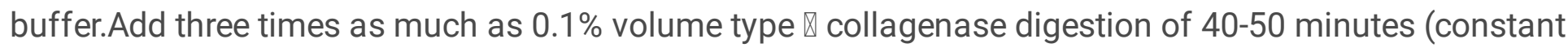
temperature level table), until fat tissue changed into shape of chyle .Centrifuge (1200r, 5 minutes), discard the upper layer of fat, then 200, 400 mesh filter successively filtration.Filtrate was collected and centrifuged again (1200r, $5 \mathrm{~min}$ ), the supernatant was discarded. Medium containing $20 \%$ fetal bovine serum was added and resuspended.The liquid was transferred to a flask for culture.

\subsection{Flow cytology identification of ADSCs:}

The third generation of ADSCs were amplified and cultured, dished and laid on a $6 \mathrm{~cm}$ plate. The cells were used for flow cytometry to observe the good state of the cells. After digestion with $0.25 \%$ trypsin for $1 \mathrm{~min}$, the digestion of the fat stem cells was terminated by complete culture medium, centrifuged at $1200 \mathrm{rpm}$ for $3 \mathrm{~min}$, and the supernatant was discarded.The cells were resuspension by PBS and blood cell count plates were used. Rat ADSCs $\left(1 \times 10^{6}\right)$ were added to PBS $800 \mathrm{ul}$ and then suspended, evenly divided into $8 \mathrm{EP}$ tubes (CD90/CD44/CD45/CD31 and their corresponding homologous antibodies were respectively tested by flow cytometry), and then mixed with the corresponding antibodies $2.5 \mathrm{ul}$, incubated in darkness at $4{ }^{\circ} \mathrm{C}$ for $60 \mathrm{~min}$. The above samples were washed twice and then suspended at $100 \mathrm{ul}$ for flow cytometry detection.

\subsection{Identification of three-line differentiation of ADSCs}

\subsubsection{Osteogenic induction and identification of rat ADSCs}

Cells were collected and inoculated according to the cell density of $5 \otimes 10^{3} \mathrm{cells} / \mathrm{cm}^{2}$ in a pre-gelatin-coated six-well plate with $2 \mathrm{ml}$ medium for each well at $37^{\circ} \mathrm{C}$ and $5 \% \mathrm{CO} 2$. The induction began when the cell fusion degree reached $60-70 \%$, medium was carefully discarded, and osteogenic induction differentiation medium preheated along the wall at $37^{\circ} \mathrm{C}$ was carefully added.Fresh preheated medium for osteogenic induction differentiation was replaced every 3 days.After 2 weeks of induction, in order to avoid osteoblasts curling and shedding as much as possible, complete fluid exchange every 3 days was replaced with half fluid exchange every 2 days until a large number of mineralized nodules were induced, and alizarin red staining was performed for identification and analysis.

2.3.2. Induction and identification of chondroblast from rat ADSCs 
Cells were collected and resuscitated by chondrogen-induced medium at the density of $5 \square 10^{5} \mathrm{cell} / \mathrm{s} / \mathrm{ml}$, then $0.5 \mathrm{ml}$ cell suspension was absorbed and transferred to a $15 \mathrm{ml}$ polypropylene centrifuge tube.The $15 \mathrm{ml}$ centrifuge tube was centrifuged at $1500 \mathrm{rpm}$ for $5 \mathrm{~min}$. The purpose was to centrifuge the cells to the bottom, unscrew the tube cap, and place them in an incubator at $37^{\circ} \mathrm{C}$ and $5 \% \mathrm{CO} 2$ for culture. The fluid was changed every 2-3 days, and the volume of the fluid was $0.5 \mathrm{ml}$ (be careful to avoid the cartilage balls).After the liquid changed, the bottom of the tube was flunked, the cartilage ball was suspended, and the tube cap was unscrewed again. The culture was normal in a $5 \% \mathrm{CO} 2$ incubator at $37^{\circ} \mathrm{C}$.Culture for about 28 days for toluidine blue staining.

\subsubsection{Adipogenic induction and identification of rat ADSCs}

Cells were collected and inoculated in the orifice plate according to the cell density of $5 \rrbracket 10^{4} \mathrm{cells} / \mathrm{cm}^{2}$. The cells were cultured at $37^{\circ} \mathrm{C}$ with $5 \% \mathrm{CO}$. When the cell fusion degree is close to or reaches $100 \%$, induction begins. The medium is carefully discarded and lipogenic induction medium $\mathrm{A}$ is added.The adipogenic medium was preheated at $37^{\circ} \mathrm{C}$ and added along the wall.(It is necessary to divide the original flask medium into $50 \mathrm{ml}$ centrifuge tube and preheat the medium to be used after packing ) liquid A was induced to be sucked away for $48 \mathrm{~h}$, and liquid $\mathrm{B}$ was added into the adipogenic induced differentiation medium preheated at $37^{\circ} \mathrm{C}$.After 24 hours of induction, liquid B was sucked away and replaced with liquid $A$ for induction.After 3 to 5 times (12 to 20 days) of alternating action between liquid $A$ and liquid $B$, culture with liquid $B$ was continued until the oil droplets in the cells were large enough to be stained with oil red 0 .

\subsection{Preparation of ECM by ADSCs}

\subsubsection{Gelatin precoating:}

Add $0.2 \%$ gelatin PBS solution 2-3ml, cover the bottom of $25 \mathrm{~cm}^{2}$ cell culture bottle, and incubate at $37^{\circ} \mathrm{C}$ for $1 \mathrm{~h}$. The excess gelatin solution was sucked out and rinsed with PBS for 3 times after being refrigerated at $4{ }^{\circ} \mathrm{C}$ overnight.Add $2-3 \mathrm{ml} 1 \%$ glutaraldehyde into the $25 \mathrm{~cm}^{2}$ cell culture bottle and evenly apply to the bottom of the cell bottle. After incubation at room temperature (RT) for 30 minutes, rinse with PBS three times to remove residual glutaraldehyde.Add $2 \mathrm{ml}$ ethanolamine into the cell bottle, cover the bottom of the bottle evenly, incubate at room temperature for 30 minutes, and extract the excess ethanolamine.PBS was gently rinsed three times, and the growth medium was added to observe the color of the medium. The medium turned purple, and then repeatedly rinsed until the medium returned to normal color.Add PBS and save for a week[5].

\subsubsection{Preparation of ECM:}

The mesenchymal stem cells for ECM were the third generation of ADSCs to $15000 / \mathrm{cm}^{2}$ density inoculated with gelatin cells bottles, three days in a fluid, cells with bottle after switch to contain liquid membrane induced ( $250 \mathrm{umol} / \mathrm{L}$ ascorbic acid medium, promote cells secreted protein, cell factor and precipitation) of the cell culture medium to continue training[10], once every three days in liquid, a week 
later to the cell culture bottle to extract (PBS solution of $0.5 \%$ Triton - 100 and $20 \mathrm{mmol} / \mathrm{L} \mathrm{NH} 4 \mathrm{OH}$ ), reaction at room temperature for $5 \mathrm{~min}$, join PBS percussion. The supernatant was gently sucked out, cell debris and extract were removed by slowly rinsing with PBS for 3 times, ECM was obtained, and 2ml containing dual-anti-pbs was added, which could be maintained at $4{ }^{\circ} \mathrm{C}$ for 4 weeks.

\subsection{ADSCs are amplified with or without the extracellular matrix}

The third generation of ADSCs were inoculated into plastic culture flask containing ECM and without ECM with a density of 15,000 cells $/ \mathrm{cm}^{2}$, respectively. Cell morphology and growth rate were observed, and the cells of the two groups were photographed and counted on day 1,3 and 5. Before counting, trypsin fully digested the cells in the culture bottle and centrifuged (1000r/5 min). After removing the supernatant solution, the same amount of medium was added to each group of cells. After full suspension, the same amount of liquid was dripped into the blood count board for counting, each group of cells was counted four times and averaged.

\subsection{Grouping and treatment of myogenic induction experiments}

ADSCs after ECM amplification were inoculated in cell bottles with a density of $15,000 / \mathrm{cm}^{2}$ and labeled as group $A$, while the same generation of ADSCs without ECM amplification were inoculated in cell bottles with the same density and labeled as group $B$ and group C.On the second day of cell inoculation, A medium containing $10 \mathrm{umol} / \mathrm{L}$-azocytosine was added to group $A$ and group $B$ to induce cell myogenic differentiation[11], and the same dose of ordinary medium without 5-azocytosine was added to group C. After three days, cells were cultured in normal medium without 5-azocytosine, and the liquid was changed every two days until the cells were full of trypsin for digestion.

2.7. Immunofluorescence detection of the expression of $\beta$-actin, Myogenic determing factor (MyoD) and Desmin in cells.

Cells were rinsed with PBS once and fixed in 4\% paraformaldehyde for $15 \mathrm{~min}$ 30min. $0.1 \%$ Triton was treated at room temperature for $15 \mathrm{~min}$.PBS was washed twice;Sealed at $5 \%$ FBS for $15 \mathrm{~min}$; The proteinactin primary antibody (Proteintech 60008-1-lg), Myod primary antibody (Proteintech 18943-1-ap) and Desmin primary antibody (Proteintech 16520-1-ap) were added to the protein and incubated at $4^{\circ} \mathrm{C}$ overnight.PBS was washed three times, $5 \mathrm{~min}$ each;Cy3-labeled anti-mouse secondary antibody (Proteintech sa00009-1) and cy3-labeled anti-rabbit secondary antibody (Proteintech sa00009-2) were added and incubated at $37^{\circ} \mathrm{C}$ for $1 \mathrm{~h}$. Hoechst was incubated at room temperature and out of light for $15 \mathrm{~min}$.Photograph under fluorescence microscope.

2.8. mRNA expressions of Myosin heavy chain (MHC), troponin, Myogein(MyoG) and Myogenic factor 5 (Myf5) were detected by RT-PCR.

2.8.1. Total intracellular RNA extraction 
Cells from groups A, B and C were collected, washed twice with $3 \mathrm{ml} \mathrm{PBS}$, and the supernatant was discarded.Add $1 \mathrm{ml}$ Trizol extraction kit to fully homogenize, rest at room temperature for $5 \mathrm{~min}$.Add 0.2 $\mathrm{ml}$ chloroform, vibrate violently for $15 \mathrm{~s}$, and rest for $3 \mathrm{~min}$.Centrifuge at $4^{\circ} \mathrm{C} 12000 \mathrm{r} / \mathrm{min}$ for $10 \mathrm{~min}$, and take the supernatant.Add $0.5 \mathrm{ml}$ isopropanol, mix well, and rest on ice for 20-30 min.Centrifuge at $4^{\circ} \mathrm{C}$ $12000 \mathrm{r} / \mathrm{min}$ for $10 \mathrm{~min}$, discard supernatant.Add $1 \mathrm{ml} \mathrm{75 \%}$ ethanol and wash the precipitate.Centrifuge at $4{ }^{\circ} \mathrm{C} 7500 \mathrm{~g}$ for $5 \mathrm{~min}$, discard supernatant.Place to dry at room temperature and dissolve rnase-free $\mathrm{H} 2 \mathrm{O}$.

\subsection{2. cDNA synthesis}

The first cDNA synthesis kit was used to synthesize cDNA: In the reverse transcription reaction system, the following reagents were added into the $0.2 \mathrm{ml}$ PCR tube, as shown in table 1 .

\section{table 1 Reverse transcription reaction system}

\begin{tabular}{|c|c|}
\hline The reagent & Volume $₫ \mathrm{ml}$ \\
\hline The total RNA & 5.0 \\
\hline Random Primer $\mathrm{p}(\mathrm{dN}) 6(0.2 \mathrm{mg} / \mathrm{ml})$ & 1.0 \\
\hline Rnase-free ddH2O & 5.0 \\
\hline \multicolumn{2}{|l|}{ 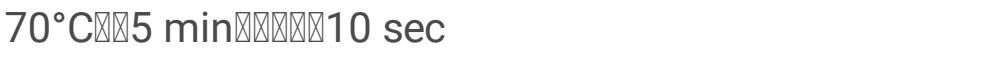 } \\
\hline $5 \times$ Reaction Buffer & 4.0 \\
\hline dNTP Mix (10 mmol/L) & 2.0 \\
\hline Rnase inhibitor (20 U/ml) & 1.0 \\
\hline AMV Reverse Transcriptase (10 U/ml) & 2.0 \\
\hline The total volume & 20.0 \\
\hline
\end{tabular}

After mixing, warm bath at $37^{\circ} \mathrm{C}$ for $5 \mathrm{~min}$. Warm bath at $42^{\circ} \mathrm{C}$ for 60 min.At $70^{\circ} \mathrm{C}$ for $10 \mathrm{~min}$, the reaction was terminated. Store the above solution at $-20^{\circ} \mathrm{C}$.

\subsubsection{Polymerase chain reaction PCR}

\subsubsection{Primer synthesis}

The primers used in real-time PCR were designed and synthesized by Primer Premier 5.0, a Shanghai biotechnology company, using the housekeeping gene GAPDH as internal reference.Primer sequences are shown in table 2.

\section{table 2 Real-timePCR primer sequence}




\begin{tabular}{ll} 
Primer & Sequence $₫ 5^{\prime}-3^{\prime} \rrbracket$ \\
\hline Mhc(mouse)-RT-F & GCATCCCTAAAGGCAGGCTC \\
\hline Mhc(mouse)-RT-R & GCCACTTGTAGGGGTTGACA \\
\hline cTn1(mouse)-RT-F & GCAGGTGAAGAAGGAGGACA \\
\hline cTn1(mouse)-RT-R & CGATATTCTTGCGCCAGTC \\
\hline Myogein(mouse)-RT-F & GAGGAAGTCTGTGTCGGTGG
\end{tabular}

\begin{tabular}{ll}
\hline Myogein(mouse)-RT-R & CCACGATGGACGTAAGGGAG \\
\hline Myf5(mouse)-RT-F & AACCCTAACCAGAGACTCCCCAAG
\end{tabular}

Myf5(mouse)-RT-R GGCAGgCTGTAATAGTTCTCCACC

\begin{tabular}{ll}
\hline Mouse GAPDH-RT-F & GGTGAAGGTCGgTGTGAACG \\
\hline Mouse GAPDH-RT-R & CTCGCTCCTGGAAGATGGTG
\end{tabular}

\subsubsection{RT- PCR reaction system}

The reaction solution was prepared according to real-time PCR reaction system.DdH2O, SybrGreen qPCR Master Mix, Forward primer, Reverse primer and cDNA template were added to the PCR reaction tube, and fully mixed.The reaction system was prepared according to table 3 .

\section{table 3 Real-time PCR system}

\begin{tabular}{|c|c|}
\hline Component & Volume(ml) \\
\hline $\mathrm{ddH} 2 \mathrm{O}$ & 7.0 \\
\hline SybrGreen qPCR Master Mix $₫ 2 \times \rrbracket$ & 10.0 \\
\hline Forward primer $10 \mathrm{mM}$ & 1.0 \\
\hline Reverse primer $10 \mathrm{mM}$ & 1.0 \\
\hline cDNA & 1.0 \\
\hline Total volume & 20.0 \\
\hline
\end{tabular}

2.8.3.3. PCR amplification: $94^{\circ} \mathrm{C}$ for $10 \mathrm{~min},\left(94^{\circ} \mathrm{C}\right.$ for 20 seconds, $55^{\circ} \mathrm{C}$ for 20 seconds, $72^{\circ} \mathrm{C}$ for 20 seconds) 40 cycles. 


\subsubsection{RT- PCR data processing}

After PCR amplification, the real-time fluorescence quantitative PCR instrument automatically analyzed the results, adjusted the threshold and baseline according to the negative control to determine the $\mathrm{Ct}$ value of each specimen, and determined whether the $\mathrm{Ct}$ value was valid according to the melting curve.Will export as a result, the 2 - delta delta CT method in gene expression differences between control group and the concentration group, computation formula as follows: delta CT = CT gene - CT inside, then obtained the control group delta CT, remember to delta CT contrast, achieve delta CT contrast average, with each group of delta CT minus delta CT contrast average, respectively obtained by delta delta CT value, namely the delta delta CT = delta - delta CT contrast CT sample, then calculate each group 2 - delta delta CT value, is the relative expression of genes in each.

\section{Statistical Analysis}

SPSS 20 software for Windows (SPSS Inc., Chicago, IL, USA) was used to record the data and for the statistical analyses. The data are presented as the means \pm standard deviations (SDs) of various measurements. Student's t test was used to compare a single experimental mean with the control mean. $\mathrm{P}<0.05$ was considered statistically significant.

\section{Results}

4.1. The results of flow cytometry were shown in figure 1.

4.2. Results of identification of differentiation of ADSCs triplex were shown in Figure 2

4.3. Results of extracellular matrix amplification of ADSCs

We used blood cell counting board to count the cells after ECM amplification and compared the number of cells under normal culture conditions. On day 1, the number of cells in plastic culture bottles without ECM and the cell bottles containing ECM were $3.4 \otimes 10^{4} / \mathrm{cm}^{2}$ and $5.7 \otimes 10^{4} / \mathrm{cm}^{2}$, respectively, showing a significant difference $(P<0.001)$. On the third day, $5.9 \otimes 10^{4}$ cells $/ \mathrm{cm}^{2}$ and $7.6 \otimes 10^{4}$ cells $/ \mathrm{cm}^{2}$ were found in the blank cell flask and the cell culture flask containing ECM $(P=0.01, p<0.05)$. On day $5,9.1 \otimes 10^{4}$ cells $/ \mathrm{cm}^{2}$ and $1.5 \otimes 10^{5}$ cells $/ \mathrm{cm}^{2}$ were found in blank cells and the cell culture flask containing ECM $(\mathrm{P}<$ 0.001).Thus, ECM can indeed significantly increase the cell proliferation rate of ADSCs. This will provide a favorable solution to the shortage of stem cells and increase the rate of cell proliferation.(Figure 3 )

4.4. The expression results of $\beta$-actin, MyoD and Desmin in cells was detected by immunofluorescence assay 
Immunofluorescence images were displayed using ImageJ software (Rawak software, Germany) and PrismDemo software (GraphPad software, USA) for statistical analysis of data: compared with group C, group $A$ and group $B$ Desmin and MyoD expression level increased significantly, in which group $A$ of cells in the content of MyoD increased 7 times $(P<0.001)$, group $B$ MyoD content increased 2.7 times $(P<$ 0.001).While between group $A$ and group $B$ the MyoD protein content also exists significant difference ( $P$ $<0.001)$. Desmin content increased by 5.2 times in group $A(P<0.001)$, and increased by 2.4 times in group $B$ compared with group $C(P<0.001)$. The difference of Desmin protein content was also significant between group $A$ and group $B(P<0.001)$.There was a difference in the content of $\beta$-actin between the groups, but the difference was not statistically significant $(P>0.05)$.(Figure 4$)$

\subsection{The mRNA expression of MyoG, Myf5, MHC and troponin.}

Rt-PCR was used to detect the mRNA expression of MyoG, Myf5, MHC and troponin of ADSCs after myoblast induction. We found that compared with group $\mathrm{C}$, the expression levels of MyoG, Myf5, MHC and troponin in group $A$ and group $B$ were significantly increased, and the mRNA expression levels of Myf 5 in group $A$ and group $B$ were increased by 2.4 times and 1.6 times respectively $(P<0.001)$. There were also significant differences in Myf5 mRNA expression between groups $A$ and $B(P<0.001)$. The mRNA expression levels of $\mathrm{MHC}$ in group $A$ and group $B$ were increased by 3.8 times and 2.3 times respectively compared with group $C(P<0.001)$. The mRNA expression levels of $\mathrm{MHC}$ also showed significant differences between groups $A$ and $B(P<0.001)$. The mRNA expression levels of cTn1 in group $A$ and group $B$ increased by 2.7 times and 1.8 times compared with group $C$, respectively, with significant difference $(P<0.001)$.The mRNA expression level of troponin was also significantly different between groups $A$ and $B(P<0.001)$.The mRNA levels of Myogein in group $A$ and group $B$ increased by 4.7 times and 2.4 times respectively compared with group $C(P<0.001)$. The mRNA expression levels of Myogein also showed significant differences between groups $A$ and $B(P<0.001)$.(Figure 5$)$

\section{Discussion}

Muscle defects and degenerative diseases affect the lives and quality of life of many patients worldwide. The administration of the drug is inefficient at regenerating damaged tissue, and the toxicity of the drug is a major blow to the patient's body.Stem cell therapy is considered a good way to repair lost cells[12].Mesenchymal stem cells (MSCs) have the ability of self-renewal, multidirectional differentiation and immune regulation, and they are the most ideal candidate cells in cell therapy and regenerative medicine[12]. MSCs are derived from many tissues囚including bone marrow [16], lung[17], fat[18], liver[19], umbilical cord[20], amniotic fluid[21], placenta[22]and umbilical cord blood[23].It has been reported that these cells have the potential to differentiate into skeletal muscle[24], cardiomyocytes[25] and smooth muscle cells[26].Among cells of various sources, ADSCs are stem cells that have been repeatedly reported and clearly possess myogenic differentiation potential, and can differentiate into muscle tissue under the action of various induction products such as 5-aza, boron and cyclic uniaxial stress[27].Among the 
several products studied, 5-aza has been shown to be a suitable inducer with stable inductivity, despite the wide variety of products studied.5-aza is a cytidine like DNA methylation inhibitor which was known to promote up-regulation of muscle genes and differentiation of hMSC[27].Previous studies have shown that it can alter cell fate and differentiate MSCs into cardiomyocytes through a specific molecular mechanism involving DNA demethylation and histone a key step in cell epigenetic modification[28]. However, due to the toxic effect of 5-aza, cell viability is limited and myoblast differentiation efficiency is not high.

Previous researches showed that ECM which maintains cellular function through complex biochemical and physical signals could significantly amplify the proliferation and improve chondrogenic potential of MSCs[5]. Studies have shown that the natural ECM not only contains collagen and fibronectin, layer adhesion proteins and macromolecular protein, polysaccharide and other proteins, it also provide physical support for the cells, a growing body of evidence indicates that the ECM can provide physical support for the cells not only, also can provide biological signals for cells, promote cell adhesion, proliferation and differentiation[29,30]. Pei et al. studied human umbilical cord blood stem cell ECM and found that ECM can improve cell proliferation, greatly improve the proliferation rate of human umbilical cord blood stem cells, and have a higher proportion of s-phase cells[31]. Our study shows that the proliferation rate of ADSCs cultured with ECM from ADSCs cells is indeed significantly higher than that of cells cultured under normal conditions(Day 1,5 P $<0.001$;Day $3 \mathrm{P}<0.05$ ). This suggests that we can use this as a routine method to maintain the self-renewal and proliferation capacity of target cells in future studies.

In our research the ECM also play a role in enhancing the myogenic differentiation potential of ADSCs.Through our experimental verification, it was found that the expression of $\beta$-actin in ADSCs amplified by ECM was not significant among the groups, and there was no statistical significance $(P>0.05)$. Actin is a part of the cytoskeleton that promotes translocation of GLUT4 and glucose transport in adult muscles[32]. This suggests that ECM does not enhance GLUT4 translocation and glucose transport in myoblasts.MyoD, MyoG and Myf5 are the production of MRFs gene family[33], belongs to the muscle specific genes, controlling muscle progenitor cells, shape and proliferation of muscle fibers to form, mature individual muscle after birth and functional whole process of the development of skeletal muscle is the most important genes in muscle development.Some researchers have found that when muscle cells encounter stimulation, they first express primary MRFs, and later express the downstream proteins desmin, myosin, etc. of mature cells[34].In MRFs, Myf5 and MyoD, which are related to myoblast hyperplasia, are first expressed, and then MyoG, which is mainly involved interminal differentiation, is expressed[35].We find that after ECM culture, the expression of Myf5 and MyoD in myoblast proliferating phase was significantly increased $(\mathrm{P}<0.001)$, and the expression of MyoG in myoblast terminal differentiation was also significantly increased $(\mathrm{P}<0.001)$.As a downstream protein of mature cells, Desmin is a muscle-specific type III intermediate fiber, which is crucial to the normal structure and function of muscles[36]. The myosin heavy chain(MHC) is the basic unit of myosin, and troponin is an important regulatory protein involved in striated muscle contraction[37]. The expressions of desmin, $\mathrm{MHC}$ and troponin in ECM cultured stem cells were significantly increased $(P<0.001)$. Therefore, we believe that 
the role of ECM in enhancing the myoblast differentiation potential of ADSCs is not only reflected in the proliferation and terminal differentiation of myoblast, but also in the framework construction and the contraction movement of muscle cells.But the mechanism is not clear how the ECM from ADSCs play a role in affecting cell proliferation and myogenic induction and further research will be performed.

This experiment also has certain limitations. Only the ADSCs cultured after ECM were subjected to the myoblast culture analysis by 5-aza method, and the myoblast induction was not conducted in the ECM co-culture environment. What's more, only cell experiments were carried out, and no further animal experiments were conducted to verify this.Next, we will conduct myoblast induction in the environment of ECM co-culture to explore whether the myoblast induction effect is better.

\section{Conclusion}

ECM is a promising approach to enhance the proliferation and myoblast differentiation potential of ADSCs.In our experiments, ADSCs cultured by ECM showed better proliferation and greater myoblast differentiation potential.It provides a new idea for us to induce myogenic differentiation of stem cells more efficiently.

\section{Declarations}

\section{Acknowledgements}

The paper was received the help from Professor Ming Pei from Stem Cell and Tissue Engineering Laboratory, Department of Orthopaedics, West Virginia University, Morgantown, WV 26506, USA.

The author also wants to thank China wuxi pu he biomedical technology company to provide technical support.

\section{Funding}

The present study was supported by funds from the Young Medical Key Talent Project of Jiangsu province (grant no. QNRc2016458), Jiangsu Provincial Medical Innovation Team (grant No. cXTdB2017004), Medical key talent project of yangzhou municipal commission of health and family planning(No.10)and clinical Study of Jiangsu University (grant No. JLY20160005).

\section{Availability of data and materials}

The datasets used and/or analyzed during the current study are available from the corresponding author on reasonable request.

\section{Ethics statment}

The study was reviewed and approved by Northern Jiangsu People's Hospital. 


\section{Authors' contributions}

The study was conceived and designed by WYF, JCW and LQY. WYF and BX conducted most of the experiments with assistance from YL,XQW ,YZ,SCC and MSL. The paper was written by BX, with contributions from WYF and MP. All authors read and approved the final manuscript.

\section{Patient consent for publication}

No patients were involved in this study.

\section{Competing interests}

The authors declare that they have no competing interests and no financial associations to disclose.

\section{References}

[1] D.J. Milner, J.A. Cameron, Muscle repair and regeneration: stem cells, scaffolds, and the contributions of skeletal muscle to amphibian limb regeneration, Curr Top Microbiol Immunol 367 (2013) 133-159.

[2] Y. Li, J. Huard, Differentiation of Muscle-Derived Cells into Myofibroblasts in Injured Skeletal Muscle, The American Journal of Pathology 161 (3) (2002) 895-907.

[3] F. Faghihi, E.M. Baghaban, A. Nekookar, M. Najar, G.H. Salekdeh, The effect of purmorphamine and sirolimus on osteogenic differentiation of human bone marrow-derived mesenchymal stem cells, Biomed. Pharmacother. 67 (1) (2013) 31-38.

[4] S. Manochantr, K. Marupanthorn, C. Tantrawatpan, P. Kheolamai, The expression of neurogenic markers after neuronal induction of chorion-derived mesenchymal stromal cells, Neurol. Res. 37 (6) (2015) 545-552.

[5] J. Li, M. Pei, A Protocol to Prepare Decellularized Stem Cell Matrix for Rejuvenation of Cell Expansion and Cartilage Regeneration, Methods Mol Biol 1577 (2018) 147-154.

[6] F. He, X. Chen, M. Pei, Reconstruction of an in vitro tissue-specific microenvironment to rejuvenate synovium-derived stem cells for cartilage tissue engineering, Tissue Eng Part A 15 (12) (2009) 3809-3821.

[7] M. Pei, J.T. Li, M. Shoukry, Y. Zhang, A review of decellularized stem cell matrix: a novel cell expansion system for cartilage tissue engineering, Eur Cell Mater 22 (2011) 333-343, 343.

[8] J. Li, F. He, M. Pei, Creation of an in vitro microenvironment to enhance human fetal synoviumderived stem cell chondrogenesis, Cell Tissue Res. 345 (3) (2011) 357-365.

[9] M. Pei, Y. Zhang, J. Li, D. Chen, Antioxidation of decellularized stem cell matrix promotes human synovium-derived stem cell-based chondrogenesis, Stem Cells Dev. 22 (6) (2013) 889-900. 
[10] T. Pizzute, Y. Zhang, F. He, M. Pei, Ascorbate-dependent impact on cell-derived matrix in modulation of stiffness and rejuvenation of infrapatellar fat derived stem cells toward chondrogenesis, Biomed. Mater. 11 (4) (2016) 45009.

[11] L.H. Okamura, P. Cordero, J. Palomino, V.H. Parraguez, C.G. Torres, O.A. Peralta, Myogenic Differentiation Potential of Mesenchymal Stem Cells Derived from Fetal Bovine Bone Marrow, Anim. Biotechnol. 29 (1) (2018) 1-11.

[12] R.L. Sohn, E. Gussoni, Stem cell therapy for muscular dystrophy, Expert Opin Biol Ther 4 (1) (2004) 19.

[13] R.W. Chan, K.E. Schwab, C.E. Gargett, Clonogenicity of human endometrial epithelial and stromal cells, Biol. Reprod. 70 (6) (2004) 1738-1750.

[14] G. Cossu, F. Mavilio, Myogenic stem cells for the therapy of primary myopathies: wishful thinking or therapeutic perspective? J. Clin. Invest. 105 (12) (2000) 1669-1674.

[15] C.H. Cui, T. Uyama, K. Miyado, M. Terai, S. Kyo, T. Kiyono, A. Umezawa, Menstrual blood-derived cells confer human dystrophin expression in the murine model of Duchenne muscular dystrophy via cell fusion and myogenic transdifferentiation, Mol. Biol. Cell 18 (5) (2007) 1586-1594.

[16] P. Antonitsis, E. loannidou-Papagiannaki, A. Kaidoglou, N. Charokopos, A. Kalogeridis, K. KouziKoliakou, I. Kyriakopoulou, I. Klonizakis, C. Papakonstantinou, Cardiomyogenic potential of human adult bone marrow mesenchymal stem cells in vitro, Thorac Cardiovasc Surg 56 (2) (2008) 77-82.

[17] V.N. Lama, L. Smith, L. Badri, A. Flint, A.C. Andrei, S. Murray, Z. Wang, H. Liao, G.B. Toews, P.H. Krebsbach, M. Peters-Golden, D.J. Pinsky, F.J. Martinez, V.J. Thannickal, Evidence for tissue-resident mesenchymal stem cells in human adult lung from studies of transplanted allografts, J. Clin. Invest. 117 (4) (2007) 989-996.

[18] D.C. Andersen, A. Kortesidis, A.C. Zannettino, I. Kratchmarova, L. Chen, O.N. Jensen, B. Teisner, S. Gronthos, C.H. Jensen, M. Kassem, Development of novel monoclonal antibodies that define differentiation stages of human stromal (mesenchymal) stem cells, Mol. Cells 32 (2) (2011) 133-142.

[19] Y. Wang, X. Yu, E. Chen, L. Li, Liver-derived human mesenchymal stem cells: a novel therapeutic source for liver diseases, Stem Cell Res. Ther. 7 (1) (2016) 71.

[20] C. Mennan, K. Wright, A. Bhattacharjee, B. Balain, J. Richardson, S. Roberts, Isolation and characterisation of mesenchymal stem cells from different regions of the human umbilical cord, Biomed Res. Int. 2013 (2013) 916136.

[21] J.A. Kim, Y.H. Shon, J.O. Lim, J.J. Yoo, H.I. Shin, E.K. Park, MYOD mediates skeletal myogenic differentiation of human amniotic fluid stem cells and regeneration of muscle injury, Stem Cell Res. Ther. 4 (6) (2013) 147. 
[22] S. Vellasamy, P. Sandrasaigaran, S. Vidyadaran, E. George, R. Ramasamy, Isolation and characterisation of mesenchymal stem cells derived from human placenta tissue, World J Stem Cells 4 (6) (2012) 53-61.

[23] Y.T. Lv, Y. Zhang, M. Liu, J.N. Qiuwaxi, P. Ashwood, S.C. Cho, Y. Huan, R.C. Ge, X.W. Chen, Z.J. Wang, B.J. Kim, X. Hu, Transplantation of human cord blood mononuclear cells and umbilical cord-derived mesenchymal stem cells in autism, J. Transl. Med. 11 (2013) 196.

[24] D. Galli, M. Vitale, M. Vaccarezza, Bone marrow-derived mesenchymal cell differentiation toward myogenic lineages: facts and perspectives, Biomed Res. Int. 2014 (2014) 762695.

[25] M.F. Pittenger, B.J. Martin, Mesenchymal stem cells and their potential as cardiac therapeutics, Circ. Res. 95 (1) (2004) 9-20.

[26] Q. Xiao, Z. Luo, A.E. Pepe, A. Margariti, L. Zeng, Q. Xu, Embryonic stem cell differentiation into smooth muscle cells is mediated by Nox4-produced H2O2, Am J Physiol Cell Physiol 296 (4) (2009) C711-C723.

[27] I. Fasolino, V. Guarino, V. Cirillo, L. Ambrosio, 5-Azacytidine-mediated hMSC behavior on electrospun scaffolds for skeletal muscle regeneration, J. Biomed. Mater. Res. A 105 (9) (2017) 2551-2561.

[28] S. Makino, K. Fukuda, S. Miyoshi, F. Konishi, H. Kodama, J. Pan, M. Sano, T. Takahashi, S. Hori, H. Abe, J. Hata, A. Umezawa, S. Ogawa, Cardiomyocytes can be generated from marrow stromal cells in vitro, J. Clin. Invest. 103 (5) (1999) 697-705.

[29] Mesenchymal Cell Chondrogenesis is Stim(Jlated by Basement Membrane Matrix and Inhibited by Age- Associated Factors.

[30] Y. Sun, T.L. Wang, W.S. Toh, M. Pei, The role of laminins in cartilaginous tissues: from development to regeneration, Eur Cell Mater 34 (2017) 40-54.

[31] X. Liu, L. Zhou, X. Chen, T. Liu, G. Pan, W. Cui, M. Li, Z.P. Luo, M. Pei, H. Yang, Y. Gong, F. He, Culturing on decellularized extracellular matrix enhances antioxidant properties of human umbilical cord-derived mesenchymal stem cells, Mater Sci Eng C Mater Biol Appl 61 (2016) 437-448.

[32] A.B. Madsen, J.R. Knudsen, C. Henriquez-Olguin, Y. Angin, K.J. Zaal, L. Sylow, P. Schjerling, E. Ralston, T.E. Jensen, beta-Actin shows limited mobility and is required only for supraphysiological insulinstimulated glucose transport in young adult soleus muscle, Am J Physiol Endocrinol Metab 315 (1) (2018) E110-E125.

[33] R.J. Bryson-Richardson, P.D. Currie, The genetics of vertebrate myogenesis, Nat. Rev. Genet. 9 (8) (2008) 632-646.

[34] P. Seale, M.A. Rudnicki, A new look at the origin, function, and "stem-cell" status of muscle satellite cells, Dev. Biol. 218 (2) (2000) 115-124. 
[35] N. Haghighipour, S. Heidarian, M.A. Shokrgozar, N. Amirizadeh, Differential effects of cyclic uniaxial stretch on human mesenchymal stem cell into skeletal muscle cell, Cell Biol. Int. 36 (7) (2012) 669-675.

[36] K. Hnia, C. Ramspacher, J. Vermot, J. Laporte, Desmin in muscle and associated diseases: beyond the structural function, Cell Tissue Res. 360 (3) (2015) 591-608.

[37] C.S. Farah, F.C. Reinach, The troponin complex and regulation of muscle contraction, FASEB J. 9 (9) (1995) $755-767$.

\section{Figures}
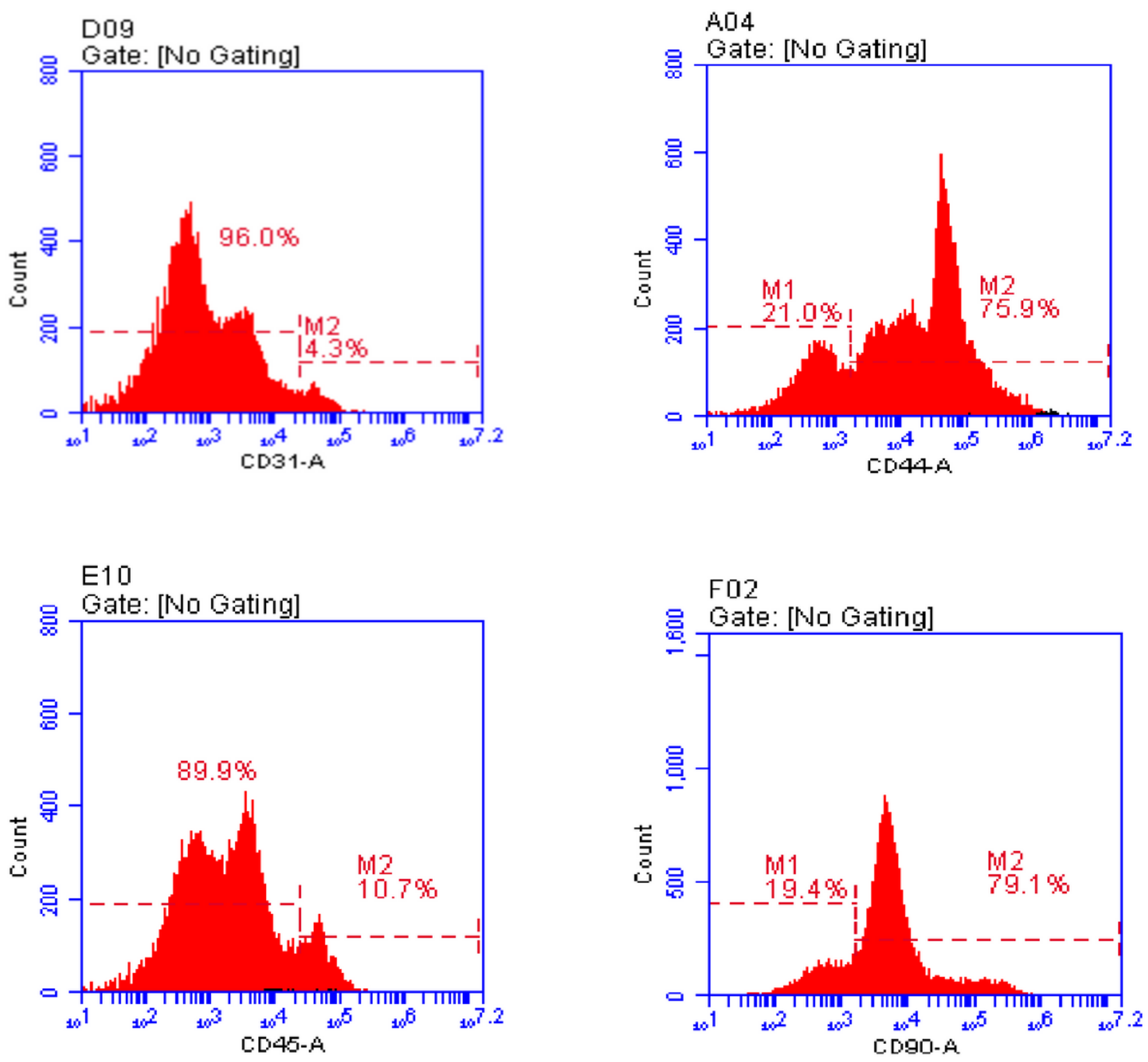


\section{Figure 1}

in the figure CD44 (75.9\%), CD90 (79.1\%). It suggests that the cells were stem cells. CD31ه4.3\%区high expression in epidermal cells. CD $45 \otimes 10.7 \%$ \high expression in vascular endothelial cells. So we can rule out epidermal cells and endothelial cells. In conclusion, the cells were highly hint as ADSCs.

A

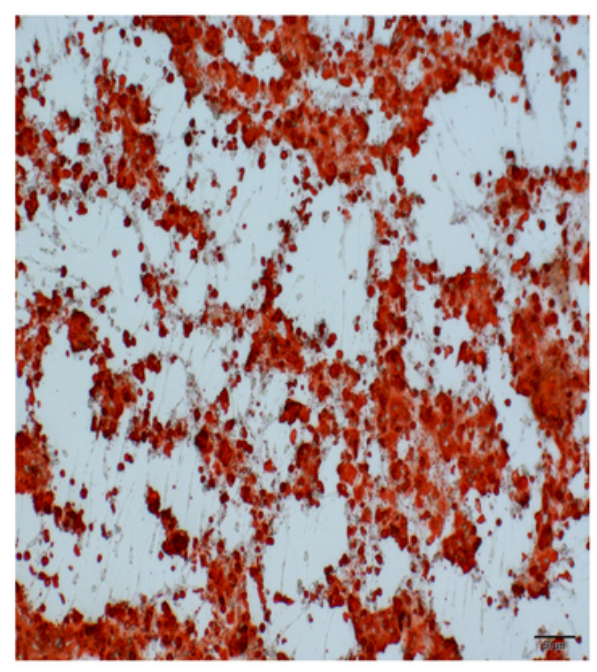

B

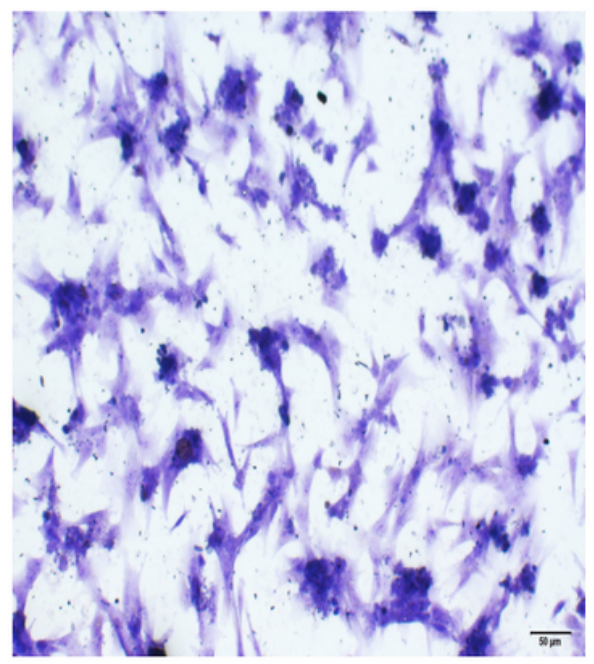

C

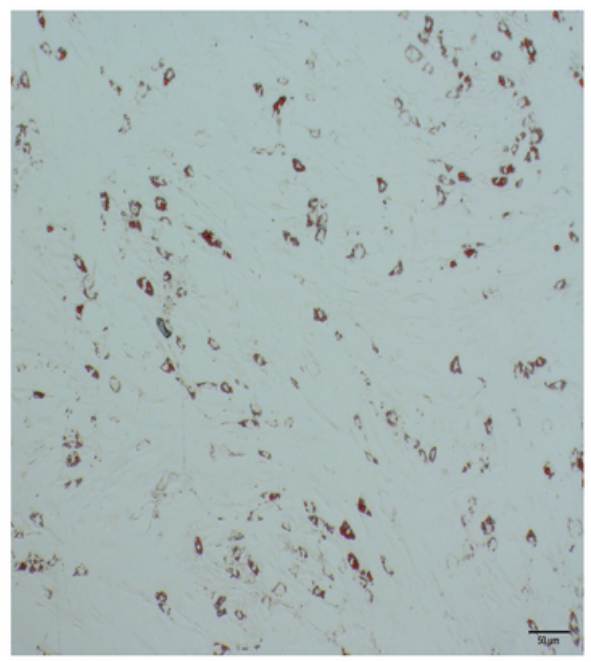

Figure 2

A shows alizarin red staining induced by osteogenesis of ADSCs, indicating that more osteoblasts appear after induction. $B$ was toluidine blue staining after chondroblast induction, and more chondrocytes were stained.C was oil red $O$ staining after lipogenic induction, and staining cells were also observed.In conclusion, this cell has the ability of three-line differentiation, which further proves that this cell is a rat ADSCs. 


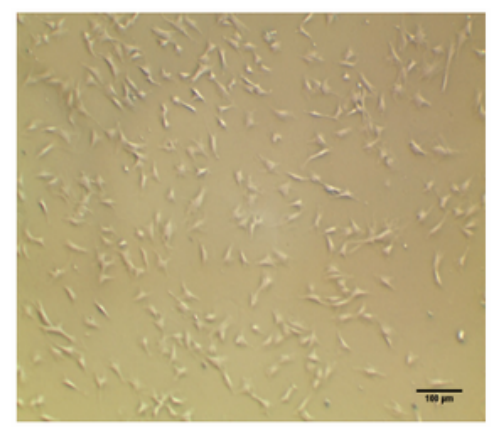

Day1

B:ECM

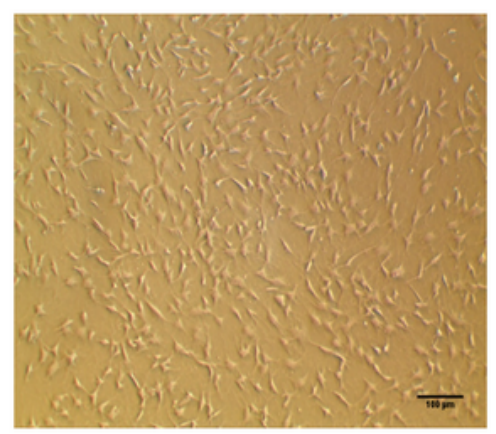

Dayl

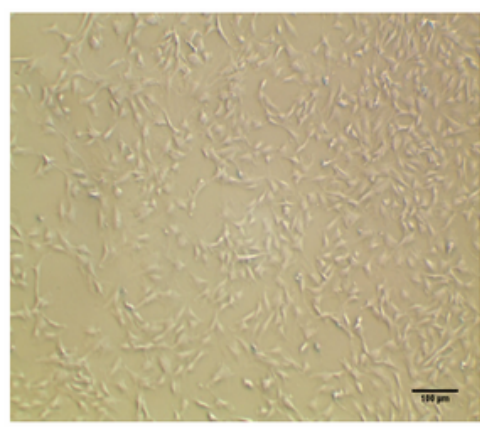

Day2

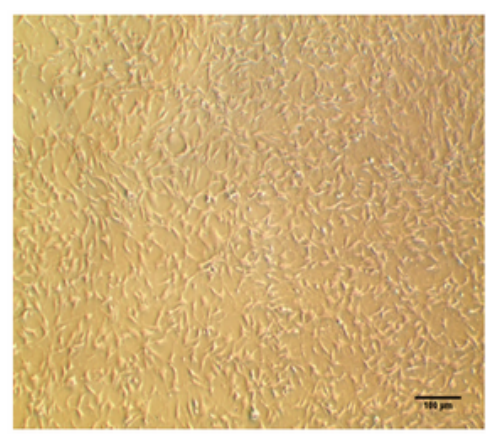

Day2

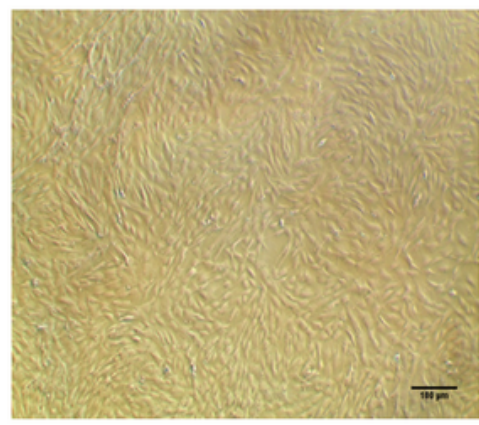

Day3

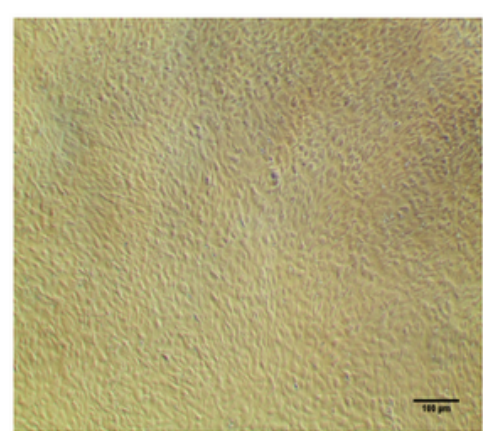

Day3

C

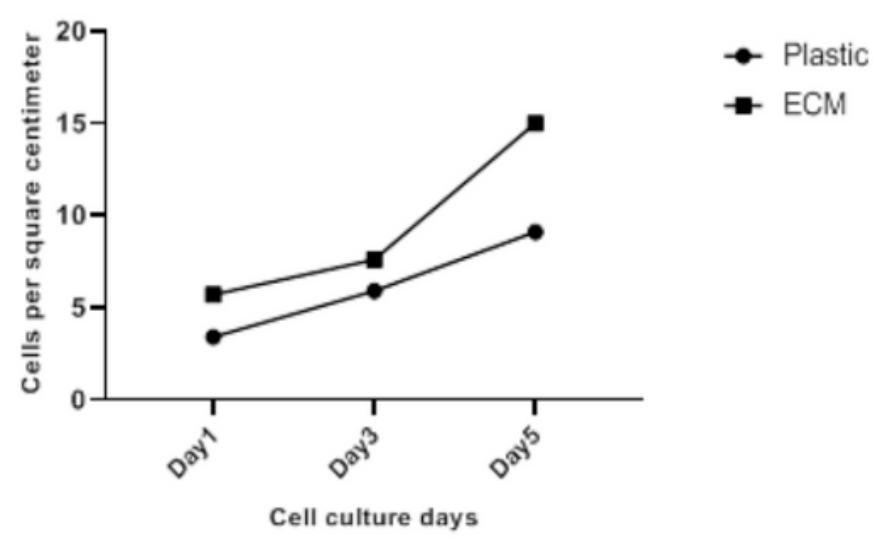

\section{Figure 3}

A and $B$ were plastic(cells without ECM) and ECM(cell bottles containing ECM), respectively, at day 1,3 and 5 were cultured under A 40-fold optical microscope.C is the cell counts of the two groups of cells on different days by using the blood cell counting plate. 
A

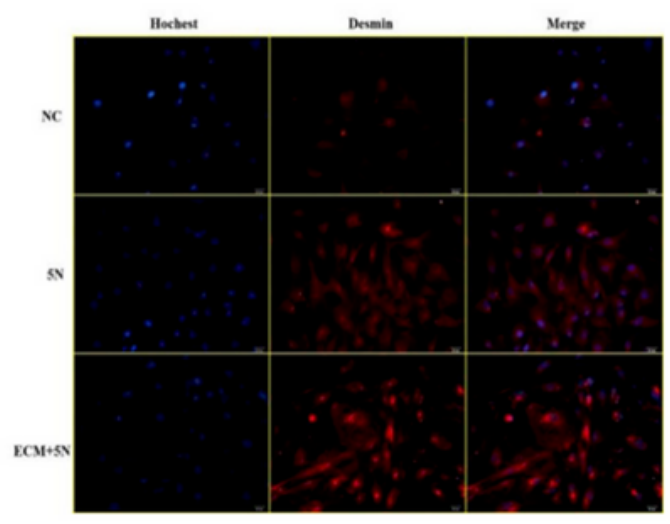

C

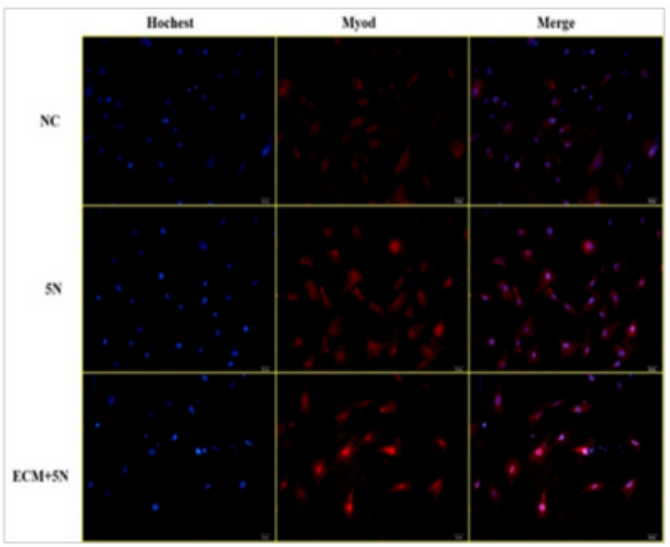

E

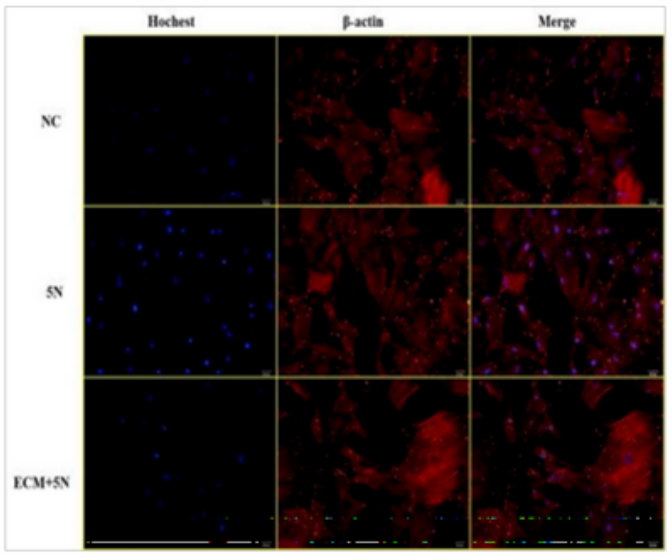

B

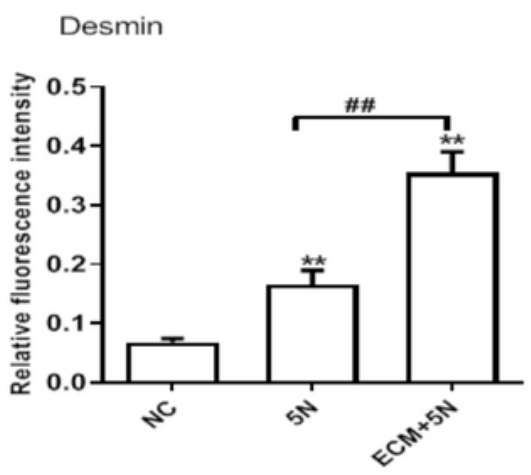

$\mathrm{D}$

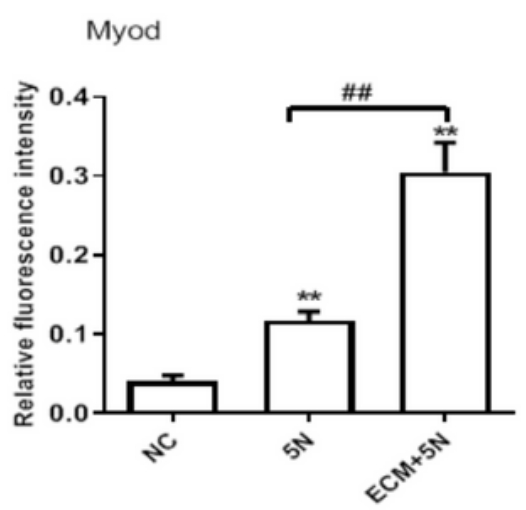

$\mathrm{F}$

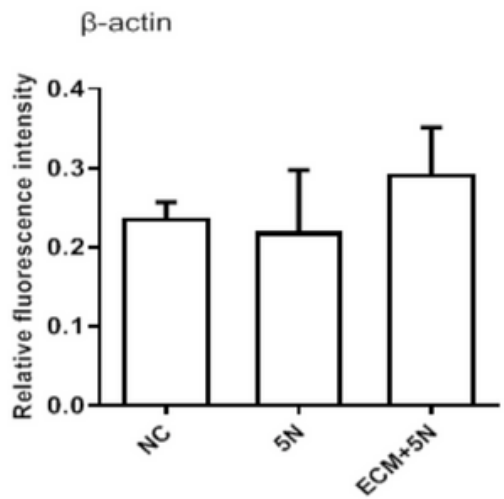

\section{Figure 4}

in the Figure( $N C$ for group $C, 5 N$ for group $B, E C M+5 N$ for group $A)$, $A$ is the Desmin fluorescence image. $B$ is the Desmin protein content, it can be seen that the protein content of group $A$ and $B$ significantly increased compared with that of group $C(P<0.001)$, and the protein content difference between group $A$ and $B$ was also significant $(P<0.001)$.C is the fluorescence picture of MyoD.D was the protein content of MyoD, and the protein content of group A and B was significantly increased compared with that of group 
$C(P<0.001)$, and the protein content of group $A$ and $B$ was significantly different from that of group $C$ $(P<0.001)$.E is the fluorescence image of $\beta$-actin.F was the content of $\beta$-actin protein, and there was no significant difference in protein content between the three groups $(P>0.05)$.
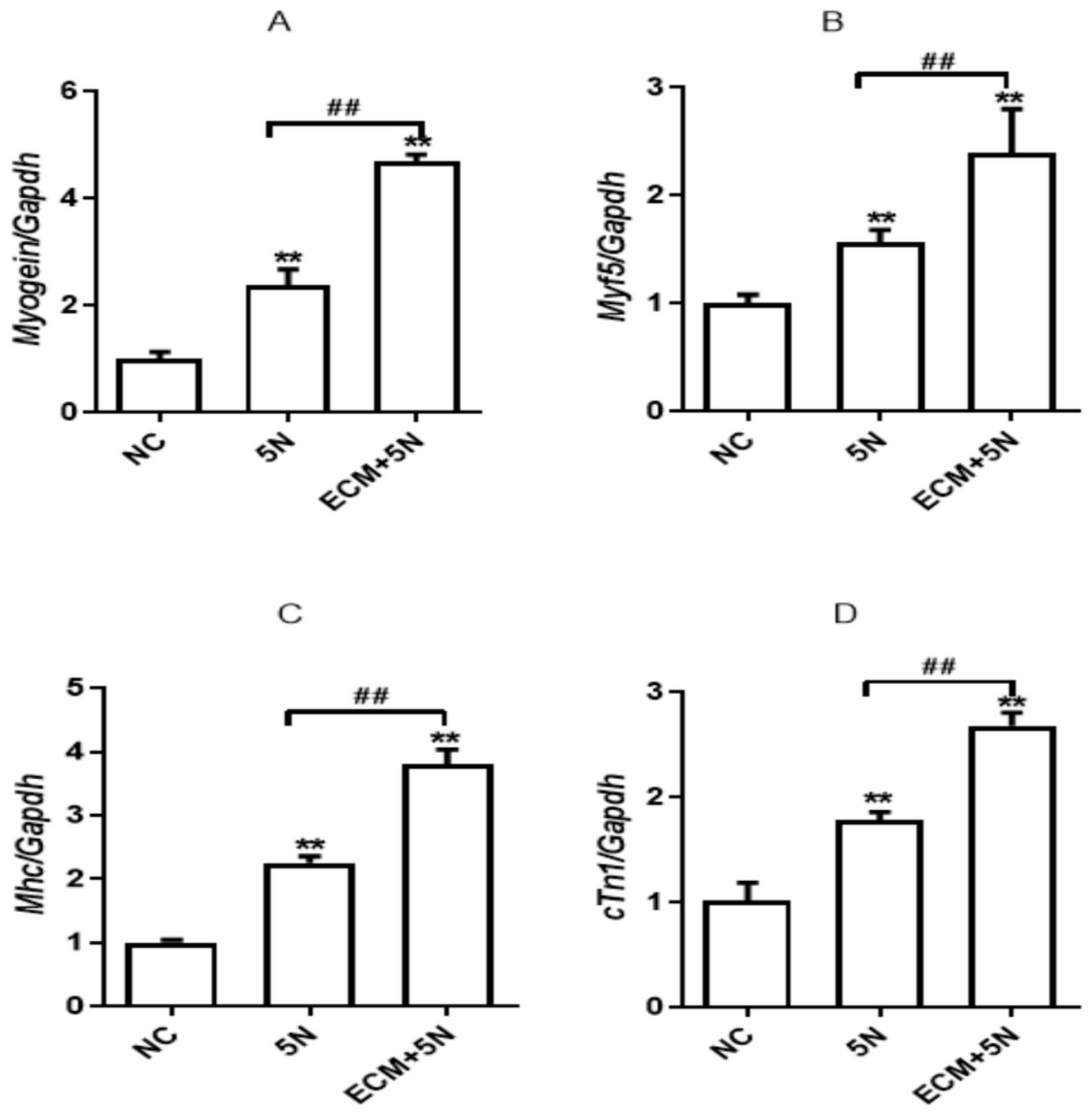

Figure 5

ADSCs myoblast induced the expression of various markers of mRNA, MyoG mRNA (A), Myf5 mRNA (B), MHC mRNA (C), troponin mRNA (D). All the indicators showed significant differences among the 
$\operatorname{groups}(P<0.001)$.

Page 20/20 